\title{
Is content king? Job seekers' engagement with social media employer branding content
}

\author{
Moser, Kilian ${ }^{\text {a,b }}$; Tumasjan, Andranik ${ }^{\mathrm{a}}$ and Welpe, Isabell M. ${ }^{\text {a }}$ \\ ${ }^{a}$ TUM School of Management, Technical University Munich, Germany \\ ${ }^{\mathrm{b}}$ Center for Digital Technlogy \& Management, Technical University Munich \& University \\ of Munich (LMU), Germany.
}

\begin{abstract}
Increasing digitization and the emergence of social media have radically changed the recruitment landscape adding interactive digital platforms to traditional means of employer communication. Removing barriers of distance and timing, social media enable firms to continue their efforts of promoting their employment brand online. However, social media employer communication and employer brand building remains woefully understudied. Our study addresses this gap by investigating how firms use social media to promote their employer brand. We analyze employer branding communication in a sample of $N=216,828$ human resources $(H R)$ related Tweets from $N=166$ Fortune 500 companies. Using supervised machine learning we classify the Tweet content according to its informational and inspirational nature, identifying five categories of employer branding social media communication on Twitter.
\end{abstract}

Keywords: Recruitment, social media, employer brand equity, Twitter, machine learning, automated text categorization.

An extended manuscript is available from the authors on request. 